\title{
Effective Dose to Patients during Cardiac Interventional Procedures (Khartoum-Sudan)
}

\author{
Eitidal Hussein. Khalafalla ${ }^{1}$, F. I. Habbani ${ }^{2}$, M. E. M. Gar-elnabi ${ }^{3}$ \\ ${ }^{1}$ Sudan Academy of Science, PO Box86, Khartoum, Sudan \\ ${ }^{2}$ Department of Physics, University of Khartoum, PO Box 321, Khartoum, Sudan \\ ${ }^{3}$ Sudan University of Science and Technology, COMRS, Khartoum, Sudan
}

\begin{abstract}
The aim of this study was to assess effective dose to a patient during cardiac procedures, such as coronary angiography (CA), percutaneous coronary interventions (PCI), percutaneous Trans venous mitral Commissurotomy (PTMC) and pacemaker. Measurements were performed on 206 patients in hospital in Khartoum using the Dose Area Product (DAP). Calculations of surface and effective dose were performed with Monte-Carlo-based program PCXMC. The mean DAP value per procedure determined in all workplaces ranged between 1.0 and $167.0 \mathrm{Gycm}^{2}$ for CA, 1.0-194.0 $\mathrm{Gycm}^{2}$ for PCI, 1.0-69 Gycm for PTMC and 1.0-56 Gycm ${ }^{2}$ for pacemaker. The effective dose was estimated in the study by using the PCXMC software, the higher and lower values were found to be (11.95, 3.32) for PCI and PTMC respectively. The results presented are comparable with those published by other authors.
\end{abstract}

Keywords: DAP, interventional cardiology, effective dose, PCI.

\section{Introduction}

The number of interventional cardiology procedures has increased rapidly in recent years. Coronary angiography (CA) and percutaneous transluminal coronary angioplasty (PTCA) are now performed widely as a matter of routine in many general hospitals [1].

The growing use of these procedures together with the fact that these procedures generally require prolonged fluoroscopy time and multiple $\mathrm{x}$ ray exposures contribute to high population doses and their associated risks.

These interventional procedures are highly justified, and the number of instances is growing all over the world. Nevertheless, due to prolonged fluoroscopy time and multiple cine imaging, population dose and associated health risks are also increasing. The potential occurrence of the deterministic effects, especially to the skin, has been the subject of great concern. Skin dose above a value of $2 \mathrm{~Gy}$, considered as a level at which radiation dermatitis may be observed, was described [2], [3]. Entrance skin dose can be directly measured with thermoluminecence dosemeters (TLDs) [4], [5] but due to varying orientation of the X-ray tube vis-a-vis the patient during the procedure, a large number of TLDs are necessary. Most studies investigating patient doses from interventional procedures were conducted using measurements with dose area product (DAP) meter. The values of dose-area product and effective dose for interventional radiology (IR) are typically larger than those used in common diagnostic X-ray examinations. According to UNSCEAR [6] from 1992 to 1995 in the USA, there were 26 reports to the Food and Drug

Administration (FDA) of radiation- induced skin injuries from fluoroscopy. In 1999, the FDA documented some 50 cases of radiation-induced burns, many patient are underwent IC procedures. Reports from the FDA's voluntary registry and other worldwide studies are continuing to detect more incidents of skin burn following IC [7], [8].

The DAP is the initial quantity not only for estimating the entrance skin dose, but for first establishing of patients' stochastic risk, characterized by effective dose $(E)$. Knowledge of radiation doses to various organs and tissues is essential, but they cannot be measured directly in patients undergoing the examination. Monte-Carlo-based computer programs are available for estimation of organ doses with reasonable accuracy, and for the calculation of effective dose when applying tissue-weighting factors [9]. For practical applications, conversion coefficients, defined as a ratio of DAP and $E$, were calculated for a wide range of X-ray spectra parameters, projection angles and patient size [10].

Only a few investigations dealing with exposure during cardiac intervention procedures have been performed in the Sudan.

The aim of present study was to estimate effective dose to patients undergoing cardiac interventional procedures.

\section{Material and Method}

The study was performed in hospital in Khartoum. The X-ray system that used to perform this types of interventional was conducted using C-arm ((Philips- Integris (Philips Medical System Cooperation, Hamburg, Germany)) serial number is 236781, normal voltage $125 \mathrm{KV}$ and permanent filtration 2.5 AL/75, the system was Manufacturing and installed in 2012. The presented study included 206 patients, 145to coronary angiography (CA), 39 to percutaneous coronary interventions (PCI), 4 to, percutaneous transvenous mitral commissurotomy (PTMC) and 18 to pacemaker. Procedures were performed by resident cardiologists, occasionally by trainees. At the hospital technicians assisted the cardiologist during the procedures. 


\section{International Journal of Science and Research (IJSR) \\ ISSN (Online): 2319-7064 \\ Index Copernicus Value (2013): 6.14 | Impact Factor (2014): 5.611}

The most common performed cardiac procedures in the hospital were selected, namely CA, for the examination of blood vessels or chambers of the heart, PCI; for treating the stenotic coronary arteries of the heart, Percutaneous Transvenous Mitral Commissurotomy (PTMC) which is carried out when a mitral valve becomes narrowed. It is a long-term complication of rheumatic fever. While rheumatic fever is becoming rare in the developed western world, in developing countries it is still a major health issue.

The last procedure was the implantation of an artificial pacemaker by physicians to correct a slow heart.

The effective and the organs doses were estimated in the study by using the PCXMC software which is based on Monte Carlo simulation. The effective dose was calculated by using the present tissue weighting factors of ICRP Publication 103 (ICRP 103, 2007). The datum includes the mean of the patient's weight, height, KAP and the beam width and height (the lateral and vertical dimensions of the beam at the skin of the patient) for each procedure, which was used for the calculation, is summarize in Table $\mathbf{1}$ the standard height and weight $(178.6 \mathrm{~cm}$ and $73.3 \mathrm{Kg}$, respectively) for adult patient which was provided by the software was used.

\section{Result}

Table1: Number of patients with their means of the weight, height, KAP and beam width and height for the cardiac procedure

\begin{tabular}{|c|c|c|c|c|}
\hline $\begin{array}{c}\text { Procedure (no } \\
\text { of patients) }\end{array}$ & $\begin{array}{c}\text { Weight } \\
(\mathrm{Kg})\end{array}$ & $\begin{array}{c}\text { Height } \\
(\mathrm{cm})\end{array}$ & $\begin{array}{c}\text { KAP } \\
\left(\mathrm{Gy} . \mathrm{cm}^{2}\right)\end{array}$ & $\begin{array}{c}\text { Beam width and } \\
\text { height }(\mathrm{cm})\end{array}$ \\
\hline CA (145) & 76.5 & 159 & 29.5 & $11.7 \times 11.7$ \\
\hline PCI(39) & 73.9 & 167.3 & 63.7 & $12.0 \times 12.0$ \\
\hline Pacemaker(18) & 69.7 & 161.8 & 18.8 & $13.0 \times 13.0$ \\
\hline PTMC (4) & 66 & 167.5 & 25.3 & $14.5 \times 14.5$ \\
\hline
\end{tabular}

Kvp $=$ 80, FSD $=90$, Aluminum filter $=3 \mathrm{~mm}$ thickness

Table2: Mean Organs and Effective Dose for cardiac procedures

\begin{tabular}{|c|c|c|c|c|}
\hline Organ & $\begin{array}{c}\text { Dose (mGy) } \\
\text { CA }\end{array}$ & $\begin{array}{c}\text { (Error \%) } \\
\text { PCI }\end{array}$ & PTMC & Pacemaker \\
\hline Brain & $0.01(1.10)$ & $0.02(1.06)$ & $0.01(1.05)$ & $0.01(1.10)$ \\
\hline Breast & $5.29(1.80)$ & $14.75(1.82)$ & $5.85(1.80)$ & $4.35(1.81)$ \\
\hline Kidney & $0.25(9.00)$ & $0.70(9.03)$ & $0.28(9.10)$ & $0.21(9.02)$ \\
\hline Lung & $9.43(1.10)$ & $26.64(1.11)$ & $10.56(1.13)$ & $7.85(1.11)$ \\
\hline Skin & $2.47(1.11)$ & $6.97(1.10)$ & $2.76(1.12)$ & $2.06(1.10)$ \\
\hline Thyroid & $0.37(17.70)$ & $1.04(17.69)$ & $0.41(17.74)$ & $0.31(17.73)$ \\
Oesophagu & $7.81(4.30)$ & $22.9(4.23)$ & $8.76(4.13)$ & $6.51(4.31)$ \\
\hline Effective & $4.29(0.70)$ & $11.95(0.69)$ & $3.52(0.71)$ & $4.74(0.70)$ \\
Dose (mSv) & & & & \\
\hline
\end{tabular}

Table 3: DAP to effective dose conversion factors $\left(\mathrm{mSv} / \mathrm{Gycm}^{2}\right)$ in this study and previous studies.

\begin{tabular}{|l|l|l|}
\hline \multirow{2}{*}{ Reference } & \multicolumn{2}{|c|}{$\left(\mathrm{mSv} / \mathrm{Gycm}^{2}\right)$} \\
\cline { 2 - 3 } & $C A$ & $P C I$ \\
\hline Current Study & 0.14 & 0.19 \\
Hart and Wall. & 0.12 & 0.26 \\
Nada et al. & 0.19 & 0.18 \\
Lobotessi et al. & 0.22 & -- \\
Betsou et al. & 0.18 & 0.18 \\
Broadhead et al. & 0.23 & 0.25 \\
Leung and Martin et al. & 0.22 & -- \\
\hline
\end{tabular}

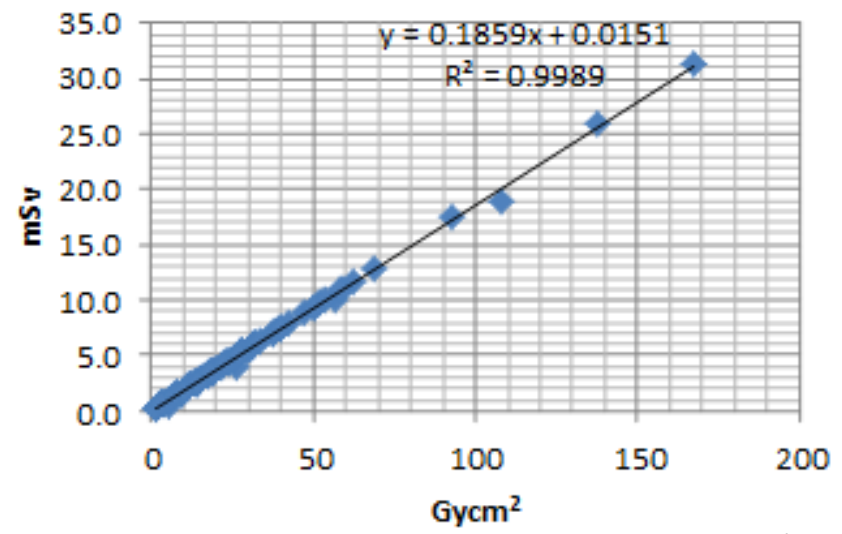

Figure 1: showed linear relationship between the Gy. $\mathrm{cm}^{2}$ and $\mathrm{mSv}$ with $\mathrm{R} 2=0.9989$ during CA procedures

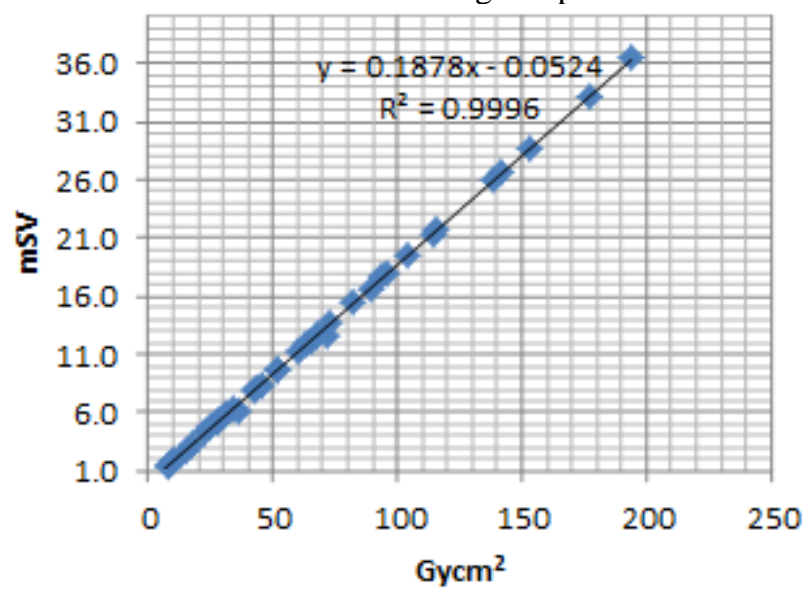

Figure 2: showed linear relationship between the Gy. $\mathrm{cm}^{2}$ and $\mathrm{mSv}$ with $\mathrm{R} 2=0.9995$ during $\mathrm{PCI}$ procedures

\section{Discussion}

The number of patients with their means of demographic data for (height and weight) and DAP and beam width and height listed in Table (1) for each procedure.

The outcome of this study was compared with some published surveys for CA and PCI as demonstrated in Table 3. The highest effective dose related to PCI possibly due to longer time associated with this procedure. The lowest effective dose related to Pacemaker because in this procedure used the fluoroscopy more than cine graphic.

Effective dose values for CA and PTMC procedures were found to be $(4.23,4.74)$ respectively. 


\section{International Journal of Science and Research (IJSR) \\ ISSN (Online): 2319-7064}

Index Copernicus Value (2013): 6.14 | Impact Factor (2014): 5.611

The calculated effective doses of this research are compared with the values presented by other workers [11] - [19]. On the basis of the results of this study, the effective dose of patients who undergo (IC) procedures are much higher than the corresponding doses arising from conventional diagnostic radiology and cardiologists should take every precautions to avoid unnecessary exposure of patients.

The outcome of this study was compared with published survey for CA, PCI and pacemaker our mean effective dose results for CA was lower than all other presented studies [9][12]. It was found to be only higher than the value presented for Nada A. Ahmed et al [20] and for PCI it was found greater than Karpinen et al [18] and Nada A. Ahmed et al [20].

Table2 shows that highest mean dose values were found for the lung (9.43, $26.64 \mathrm{mGy}$ ) for CA and PCI respectively, an organ which is directly impacted by the primary $\mathrm{x}$-ray beam during the procedure. The oesophagus's mean dose value was found to be $(7.81,22.9)$, while the breast mean dose of (5.29, 14.75) and breast $(0.01,0.02)$ for CA and PCI respectively. Does were much lower, these organs being less frequently exposed to nigh x-ray intensity due to their anatomical position and the x-ray detector side.

The study provided that absorbed doses received during heart such as lungs, oesophagus and breasts could be relatively with a wide range of does. The relation between the obtained mean $\mathrm{E}$ values and mean DAP values in this study lead to conversion factors in $\mathrm{mSv} / \mathrm{Gycm}^{2}$ for the cardiac procedure equal to $0.14,0.19,0.18$ and 0.19 for CA, PCI, PTMC and pacemaker respectively The outcome of this study was compared with some published surveys [13], [17], [20] [23].Table3 shows values for conversion factors from literature for CA and PCI. The obtained conversion factors in this study were close to the values reported by Hart and Wall [21], Nada A. Ahmed et al [20] and Betsou et al [13].

Figure: 1 showed the linear correlation between the DAP and effective dose in direct relationship noted with significant association which increased by $0.186 \mathrm{mGy} / \mathrm{cm}^{2}$ for every one $\mathrm{mSv}$ increment in tube voltage when the mean value of DAP where equal to 29.5 with $\mathrm{R} 2=0.998$, and the linear regression equation that can describe this correlation was $\mathrm{y}=0.186 \mathrm{x}+0.015$ during $\mathrm{CA}$ procedures. This was compared with the relation in PCI procedure when the mean value of DAP and Effective dose were 63.7 and 11.95respectively. In more strong correlation that PCI where the R2= 0.999 (figure2).

To optimize radiation protection, every effort should be made to reduce the DAP of a procedure and thus the effective dose to the patients. This goal can be primarily achieved in this hospital by: (1) intensive training of the operators, nurses and technologists (2) position to the region of interest only and shift to lower cine-graphic modes and use less cinegraphic runs, (3) Use low-level fluoroscopy mode whenever possible and reduce the fluoroscopy time as possible (4) Avoid unnecessary magnification, (5) Apply the "as low as reasonably achievable" (ALARA) principle in emergency cases after gaining sufficient reperfusion.

\section{Conclusion}

The study presents results for 206 patients undergoing cardiac interventional procedures at hospital in Khartoum during 10 months. This study has shown that the doses received by patients during IC procedures could be high, especially since these patients could be exposed several times according to the chronic evolution of the coronary disease. A careful radiation protection approach is needed for those patients in order to reduce, their exposure to ionizing radiation. Health monitoring as well as long-term epidemiological studies of the most exposed patients undergoing IC procedures should help to assess the radiationinduced cancer risk of the radiosensitive organs around the heart, but need to take into account the clinical specificities of the target population. The results of this work correspond to other published data and confirm the fact that cardiology procedures may result in an increased risk compared with most radiological examinations.

\section{References}

[1] Struelence L., Vanhavere F., Bosmans H. (2005) Effective doses in angiography an interventional radiology: calculation of conversion coefficients for angiography of the lower limbs. Br. J. Radiol 78:135142.

[2] International Commission on Radiation Protection. Avoidance of skin injuries from medical interventional procedures. ICRP Publication 85. Ann. ICRP 30 (Oxford: Pergamum Press) (2001).

[3] Faulkner, K. and Vano, E. Deterministic effects in interventional radiology. Radiat. Prot. Dosim. 94, 9598 (2001).

[4] Waite, J. C. and Fitzgerald, M. An assement of methods for monitoring entrance surface dose in fluoroscopically guided interventional procedures. Radiat. Prot. Dosim. 94, 89-92 (2001).

[5] Mooney, R. B. Skin dose to patients from interventional radiology and cardiology procedures with potentially long fluoroscopy times. Radiat. Prot. Dosim. 90, 123126 (2000).

[6] UNSCEAR. Sources and effects of ionizing radiation. United Nations Scientific Committee on the Effects of Atomic Radiation Report to the General Assembly with Scientific Annexes. (United Nations) (2000).

[7] Vaño', E., Arranz, L., Sastre, J. M., Moro, C., Ledo, A., Garate, M. T. and M1 'nguez, I. Dosimetric and radiation protection considerations for some cases of patient skin injuries in interventional cardiology. Br. J. Radiol. 71, 510-516 (1998).

[8] Sovik, E., Klow, N. E., Hellesnes, J. and Lykke, J. Radiation-induced skin injury after percutaneous transluminal, coronary angioplasty. Case report. Acta Radiol. 37, 305- 306 (1996).

[9] Servomaa, A. and Tapiovaara, M. Organ dose calculation in medical X-ray examinations by the program PCXMC. Radiat. Prot. Dosim. 80, 213- 219 (1998).

[10] Schmidt, P. W. E., Dance, D. R., Skinner, C. L., Smith, I. A. C. and McNeill, J. G. Conversion factors for the 
estimation of effective dose in paediatric angiography. Phys. Med. Biol. 45, 3095-3107 (2000).

[11] Neofotistou, V., Karoussou, A., Lobotesi, H. and Hourdakis, K. Patient dosimetry during interventional cardiology procedures. Radiat. Prot. Dosim. 80, 151154 (1998).

[12] Neofotistou, V. Review of patient dosimetry in cardiology. Radiat. Prot. Dosim. 94, 177 - 182 (2001).

[13] Betsou, S., Efstathopoulos, E. P., Katritsis, D., Faulkner, $K$. and Panayiotakis, G. Patient radiation doses during cardiac catheterization procedures. Brit. J. Radiol. 71, $634-639$ (1998).

[14]Efstathopulos, E. P., Makrygiannis, S. S., Kottou, S., Karvouni, E., Giazitzoglou, E., Korovesis, S., Tzanalaridou, E., Raptou, P. D. and Katritsis, D. G. Medical personnel and patient dosimetry during coronary angiography and intervention. Phys. Med. Biol. 48, 3059 - 3068 (2003).

[15] Viktorie Stisova. EFFECTIVE DOSE TO PATIENT DURING CARDIAC INTERVENTIONAL PROCEDURES (PRAGUE WORKPLACES). doi:10.1093/rpd/nch336 Vol. 111, No. 3, pp. 271-274 (2004).

[16] M. T. Bahreyni Toossi. ORGAN AND EFFECTIVE DOSES OF PATIENTS ARISING FROM CORONARYANGIOGRAPHYAND

PERCUTANEOUS TRANSLUMINAL
CORONARYANGIOPLASTYAT TWO HOSPITALS IN MASHHAD-IRAN. doi:10.1093/rpd/ncm366 Vol. 128, No. 3, pp. 363366(2008).

[17] Broadhead, D. A., Chapple, C. L. and Faulkner, K. The impact of cardiology on the collective effective dose in the North of England. Br. J. Radial. 70, 492-497 (1997).

[18] Karpinnen, J., Parviainen, T., Servomaa, A. and Komppa, T. Radiation risk and exposure of radiologists and patients during coronary angiography and percutaneous transluminal coronary angioplasty (PTCA). Radiat. Prot. Dosim.57, 481-485 (1995).

[19] Katritsis, D., Efstathopoulos, E., Betsou, S., Korovesis, S., Faulkner, K., Panayiotakis, G. and Webb-Pepole, M. M. Radiation exposure of patients and coronary arteries in the stent era: a prospective study. Catheter. Cardiovasc. Interv. 51, 259-264 (2000).

[20] Nada A Ahmed. Patient Radiation Dose Assessment in Interventional radiology Procedures.69-70 (2013)

[21] Hart and Wall B. Radiation exposure of the UK population from medical and dental x-ray examinations, NRPB-W14. (2002).

[22] Lobotessi H, Karoussou A, Neofotistou V, Louisi A, Tsapaki V. Effective dose to patient undergoing coronary angiography. Radiat. Prot. Dosimetry. Vol.94, No. 1-2:173-176 (2001).

[23] Leung $\mathrm{K}$ and Martin C. Effective dose for coronary angiography. British journal of Radiology.69:426-431. 